University of South Carolina

Scholar Commons

$11-15-2007$

\title{
Relationship Between Vegetation Biophysical Properties and Surface Temperature Using Multisensor Satellite Data
}

\author{
Seungbum Hong \\ University of South Carolina - Columbia \\ Venkataraman Lakshmi \\ University of South Carolina - Columbia, vlakshmi@geol.sc.edu \\ Eric Small
}

Follow this and additional works at: https://scholarcommons.sc.edu/geol_facpub

Part of the Earth Sciences Commons

\section{Publication Info}

Published in Journal of Climate, Volume 20, 2007, pages 5593-5606.

Hong, S., Lakshmi, V., \& Small, E. E. (2007). Relationship between vegetation biophysical properties and surface temperature using multisensor satellite data. Journal of Climate, 20, 5593-5606.

(c) Copyright 2007 AMS

This Article is brought to you by the Earth, Ocean and Environment, School of the at Scholar Commons. It has been accepted for inclusion in Faculty Publications by an authorized administrator of Scholar Commons. For more information, please contact digres@mailbox.sc.edu. 


\title{
Relationship between Vegetation Biophysical Properties and Surface Temperature Using Multisensor Satellite Data
}

\author{
Seungbum Hong and Venkat Lakshmi \\ Department of Geological Sciences, University of South Carolina, Columbia, South Carolina \\ ERIC E. SMALL \\ Department of Geological Sciences, University of Colorado, Boulder, Colorado
}

(Manuscript received 4 January 2006, in final form 23 February 2007)

\begin{abstract}
Vegetation is an important factor in global climatic variability and plays a key role in the complex interactions between the land surface and the atmosphere. This study focuses on the spatial and temporal variability of vegetation and its relationship with land-atmosphere interactions. The authors have analyzed the vegetation water content (VegWC) from the Advanced Microwave Scanning Radiometer for EOS (AMSR-E), the leaf area index (LAI), the normalized difference vegetation index (NDVI), the land surface temperature (Ts), and the Moderate Resolution Imaging Spectroradiometer (MODIS). Three regions, which have climatically differing characteristics, have been selected: the North America Monsoon System (NAMS) region, the Southern Great Plains (SGP) region, and the Little River Watershed in Tifton, Georgia. Temporal analyses were performed by comparing satellite observations from 2003 and 2004. The introduction of the normalized vegetation water content (NVegWC) derived as the ratio of VegWC and LAI corresponding to the amount of water in individual leaves has been estimated and this yields significant correlation with NDVI and Ts. The analysis of the NVegWC-NDVI relationship in the above listed three regions displays a negative exponential relation, and the Ts-NDVI relationship (TvX relationship) is inversely proportional. The correlation between these variables is higher in arid areas such as the NAMS region, and becomes less correlated in the more humid and more vegetated regions such as the area of eastern Georgia. A land-cover map is used to examine the influence of vegetation types on the vegetation biophysical and surface temperature relationships. The regional distribution of vegetation reflects the relationship between the vegetation biological characteristics of water and the growing environment.
\end{abstract}

\section{Introduction}

It has been long recognized that atmospheric and land surface processes are correlated with each other. Climate and meteorological processes determine land surface characteristics such as the vegetation distribution, energy balance, and watershed hydrology (Neilson 1986; Lu et al. 2001; Small and Kurc 2003; Weiss et al. 2004). Land surface processes in turn affect atmospheric temperature, humidity, precipitation, and radiative transfer (Pielke et al. 1998; Lu et al. 2001, Weiss et al. 2004). Various studies have dealt with these interactions, including the development of land-atmosphere

Corresponding author address: Dr. Seungbum Hong, Department of Geological Sciences, University of South Carolina, Columbia, SC 29208-0000.

E-mail: shong@geol.sc.edu

DOI: 10.1175/2007JCLI1294.1

(C) 2007 American Meteorological Society models (Noilhan and Planton 1989; Pitman 1991; Xue et al. 1991) and the relation of vegetation dynamics to other land and climate variables (Betts et al. 1997; Bounoua et al. 1999; Weiss et al. 2004).

Meteorological and climatological conditions both impact and are influenced by vegetation distribution and dynamics (Sellers et al. 1996; Betts et al. 1997; Bounoua et al. 1999). For example, the rooting depth of plants varies with climate (Schenk and Jackson 2002). In turn, rooting depth influences the vertical distribution of water within the soil column and, hence, transpiration and evaporation (Kleidon and Heimann 1998; Pielke 2001). Land-cover changes have modified a large portion of the earth's terrestrial surface and biosphere (Schlesinger et al. 1990; Swetnam and Betancourt 1998), and these changes are often accompanied by changes in the biochemical and biophysical properties of vegetation. It is believed that the anthropogenic 


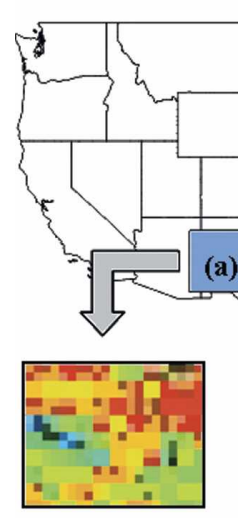

(a) NAMS

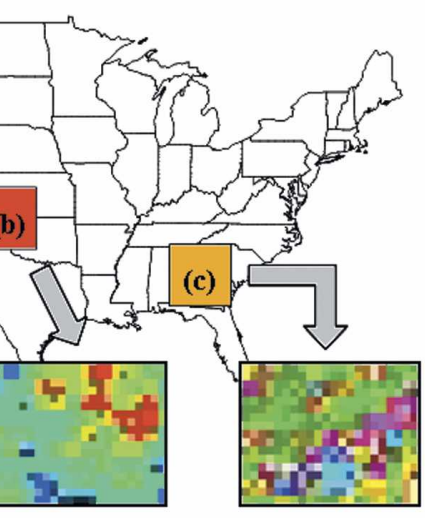

(b) IHOP
Land cover type codes

(IGBP classification):

1. evergreen needleaf forests

2. evergreen broadleaf forests

3. deciduous needleaf forests

4. deciduous broadleaf forests

5. mixed forests

6. closed shrubland

7. open shrubland

8. woody savannas

9. savannas

10. grasslands

11. permanent wetlands

12. croplands

(c) Tifton, GA 13. urban and built-up lands

FIG. 1. Study regions $(500 \mathrm{~km} \times 500 \mathrm{~km}$ spatial resolution $)$ and land-cover maps.

changes in land cover affect the local meteorology such as cloud cover, precipitation, surface hydrology, and surface temperature (Pielke et al. 1999).

Vegetation has been monitored over broad areas with the development of satellite remote sensing (Nemani et al. 1993; Tucker 1979). Vegetation in these studies has been quantified using normalized difference vegetation index (NDVI), leaf area index (LAI), vegetation water content (VegWC), and other metrics. NDVI and LAI have been used to characterize the type and amount of vegetation that exists (Zeng et al. 2000) and to evaluate the relationship of vegetation to hydrometeorological variables such as surface temperature (Goetz 1997). More recently, researchers have attempted to estimate VegWC by introducing satellitederived variables such as normalized difference water index retrieved in near-infrared channels of satellite sensors (Ceccato et al. 2001; Zarco-Tejada et al. 2003). Vegetation water content for individual plants is a useful measure of a plant's physiological state, especially when coupled with other measurements (Kramer and Boyer 1995). The utility of remotely sensed VegWC to describe vegetation processes has not yet been completely evaluated.

The goal of this paper is to examine the relationship of VegWC to other vegetation properties, both spatially and temporally, and to provide a statistical analysis of the relationship between vegetation properties and surface temperature. The physical properties of vegetation described by satellite-derived NDVI, LAI, and $\mathrm{VegWC}$ are examined seperately for different vegetation types. We focused on the summer season (June-September), corresponding to the period of maximum vegetation activity in the regions analyzed. We examined the following three basic research questions:
1) Higher leaf area index is equivalent to more leaf layers, implying more water is stored in plant canopies. Do LAI and VegWC covary, and if so what is the nature of the relationship?

2) Are plants that have high water content greener than those with low water content?

3) Surface temperature tends to decrease as NDVI increases, as summarized by the Ts and NDVI relationship (TvX; Goetz 1997). Does surface temperature also decrease as VegWC increases?

The paper is organized as follows. Section 2 is a detailed description of the satellite remote sensing datasets and the study regions. Section 3 includes a description of the analyses corresponding to each of the three research questions listed above. The major conclusions of this work and outstanding issues are discussed in section 4 .

\section{Data and methods}

\section{a. Study regions}

Three regions have been selected to examine the spatial variations of the land surface variables (Fig. 1): 1) the North American Monsoon System (NAMS) region; 2) Southern Great Plains (SGP) region, and 3) the Little River Watershed in Tifton, Georgia. The geographic latitude and longitude of their center points are $33.5^{\circ} \mathrm{N}, 107.5^{\circ} \mathrm{W} ; 36.5^{\circ} \mathrm{N}, 100.0^{\circ} \mathrm{W}$; and $32.4^{\circ} \mathrm{N}, 84.0^{\circ} \mathrm{W}$, respectively. The NAMS region has been the focus of numerous studies on the interactions between meteorology, vegetation, and land surface fluxes (Kurc and Small 2004; Weiss et al. 2004). Generally the onset of the North American Monsoon occurs in June or early July and continues into September (Weiss et al. 2004). The SGP region has also been studied to compare the 


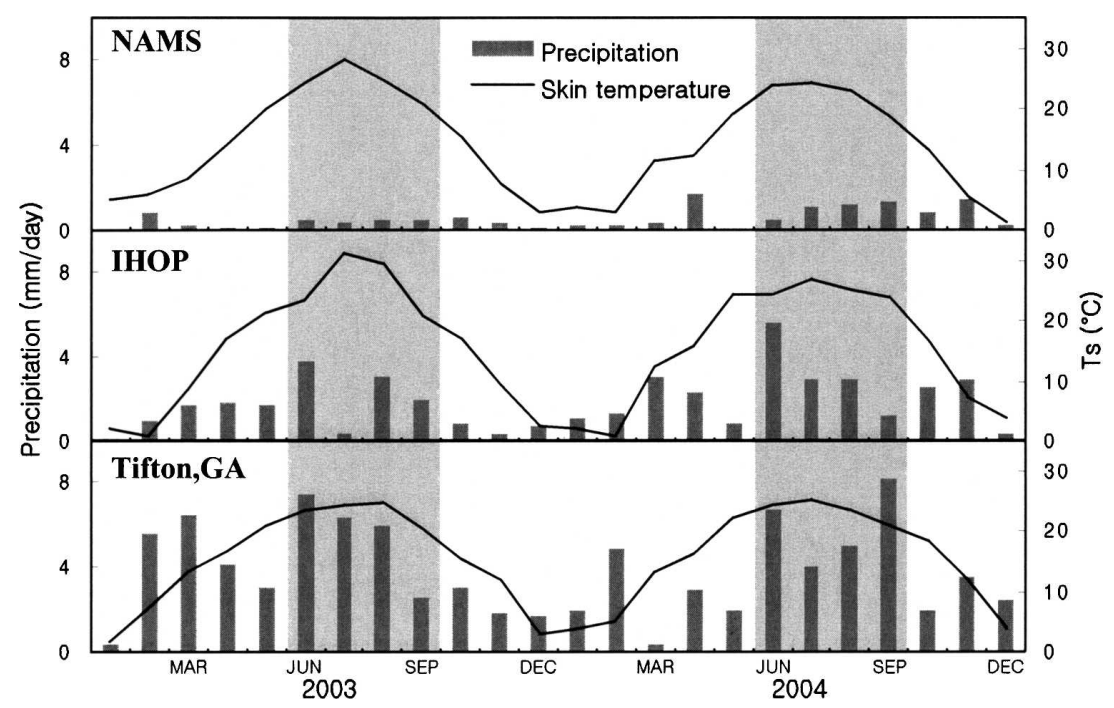

FIG. 2. Variation of precipitation and surface skin temperature (monthly averaged rate via www.cdc.noaa.gov).

climatic changes to that of the NAMS region (Weckwerth et al. 2004). The SGP region with the onset of the monsoon in this region shows climatically contrasting changes. The SGP, for example, receive more precipitation than the NAMS region, but the rainiest months are in the spring rather than the summer. The decrease in rainfall in the plains is generally concomitant with the onset of the NAM (Weckwerth et al. 2004). For the atmospheric research related with surface moisture in the $\mathrm{SGP}$ region, the International $\mathrm{H}_{2} \mathrm{O}$ Project (IHOP) has been undertaken since 2002 (Weckwerth et al. 2004). The Little River Watershed region around Tifton, as one of the highly vegetated regions in East Coast areas, has been a subject for soil moisture research. This region has a humid climate and denser vegetation than the NAMS and SGP regions. Because of the shortterm but very frequent rainfall events in summer, it has large inundated areas with mixed forests (Bosch et al. 1999). The satellite data have been processed in equalsized areas $(500 \mathrm{~km} \times 500 \mathrm{~km})$ for those study regions, and they are referred to as follows: the NAMS region, the IHOP region, and Tifton. Figure 2 shows typical climatic trends of the three regions. The NAMS region is relatively dry with a relatively low vegetation amount. Major types of vegetation in this region are shrublands with limited grasslands and crops. The IHOP region, in contrast, shows relatively more humid climate with more vegetation, which is grasslands, crops, and limited trees. Tifton is highly vegetated with mixed forest (e.g., pines and hardwoods) and crops (e.g., peanuts and cotton), showing wet and humid climate with highly frequent rainfalls.

\section{b. MODIS}

The Moderate Resolution Imaging Spectroradiometer (MODIS) has been designed for the needs of global change research with improved capability for terrestrial satellite remote sensing (Justice et al. 1998). MODIS flies on board the Terra and Aqua satellite platforms, which were launched on 18 December 1999 and on 4 May 2002, respectively. These satellites, which are sun-synchronous polar orbiting, pass from north to south across the equator at 1030 LST (Terra) and at 1330 LST (Aqua). MODIS provides 44 global data products for land, ocean, and atmospheric variables with 36 spectral bands between 0.405 and $14.385 \mu \mathrm{m}$. Its spatial resolution at nadir is 250 (bands 1-2), 500 (bands 3-7), and $1000 \mathrm{~m}$ (bands 8-36; Justice et al. 1998, 2002). [The algorithms of the MODIS land data are available at the MODIS Web site (see online at http:// modis.gsfc.nasa.gov), and we downloaded the land data, NDVI, Ts, LAI, and land-cover map (MODIS datasets used from the database are MOD13A2.4, MOD11A1.4, MOD14A2.4, and MOD12Q1.4, respectively) from the Land Processes Distributed Active Archive Center Web site (see online at http://edcdaac. usgs.gov) for this study.]

NDVI is a biophysical parameter that quantifies the photosynthetic activity of vegetation by observing the "greenness" of the vegetation, which is related to the chlorophyll abundance and energy absorption (Tucker 1979; Myneni et al. 1995). NDVI has been widely used for various studies on dynamic land surface changes such as deforestation and drought and as an important 
TABLE 1. The IGBP classification scheme (Friedl et al. 2002).

\begin{tabular}{ll}
\hline \hline & IGBP land-cover units \\
\hline Natural vegetation & $>60 \%$ cover, height exceeding $2 \mathrm{~m}$, green all year \\
1. Evergreen needleleaf forests & $>60 \%$ cover, height exceeding $2 \mathrm{~m}$, green all year \\
2. Evergreen broadleaf forests & $>60 \%$ cover, height exceeding $2 \mathrm{~m}$, annual leaf on-off cycle \\
3. Deciduous needleleaf forests & $>60 \%$ cover, height exceeding $2 \mathrm{~m}$, annual leaf on-off cycle \\
4. Deciduous broadleaf forests & $>60 \%$ cover, height exceeding $2 \mathrm{~m}$, mixed four forest types \\
5. Mixed forests & $>60 \%$ cover, less than $2 \mathrm{~m}$ tall, evergreen or deciduous \\
6. Closed shrublands & $10 \%-60 \%$ cover, less than $2 \mathrm{~m}$ tall, evergreen or deciduous \\
7. Open shrublands & $30 \%-60 \%$ cover, height exceeding 2 m, evergreen or deciduous \\
8. Woody savannas & $10 \%-30 \%$ cover, height exceeding $2 \mathrm{~m}$, evergreen or deciduous \\
9. Savannas & $<10 \%$ cover \\
10. Grasslands & Mixture of water and vegetation \\
11. Permanent wetlands & \\
Developed and mosaic lands & Temporary crops by harvest and bare soil period \\
12. Croplands & Buildings and other man-made structures \\
13. Urban and built-up lands &
\end{tabular}

variable to model simulations such as land surface hydrology and land-atmosphere interactions. NDVI is used to compute various biophysical variables such as biomass and green cover (Huete et al. 2002). It is derived using the normalized ratio of the red and nearinfrared surface reflectances (Tucker 1979). In this study, we have used MODIS Terra 16-day aggregated NDVI datasets at $1-\mathrm{km}$ spatial resolution.

The distribution of vegetation cover on global and continental scales has been investigated in many studies from satellite-derived data and field measurements (Defries et al. 1998; Hansen et al. 2000). The MODIS land-cover map uses all available spectral, temporal, directional, and spatial information from other MODIS datasets (Friedl et al. 2002). The land-cover maps have been a very important tool for global- and continentalscale studies of climate and biogeochemistry, and NDVI and LAI have been important variables to derive these land-cover maps (Myneni et al. 2002). Landcover maps derived from MODIS were used in this study and follow the International GeosphereBiosphere Program (IGBP) classification for landcover types (Friedl et al. 2002). Table 1 provides the land-cover units with accompanying descriptions.

MODIS also provides surface temperature (Ts), which is derived from thermal infrared data (Justice et al. 1998; Wan and Li 1997). Surface temperature is an important variable linking evapotranspiration (ET) to soil moisture availability. Lower soil moisture and ET yield higher surface temperature and greater sensible heating of the atmosphere (Small and Kurc 2003). We used daily values (10:30am equatorial overpass) from the daily $1-\mathrm{km}$ resolution Ts data of MODIS (Terra platform product MOD11A1.4). LAI is defined as the one-sided green leaf area per unit ground area in broadleaf canopies and as the projected needle leaf area in coniferous canopies (Myneni et al. 2002). LAI affects the fluxes of energy, mass, and momentum between the surface and the planetary boundary layer (Justice et al. 1998). The MODIS LAI is derived from a vegetation land-cover classification and MODIS surface reflectance (Justice et al. 1998; Myneni et al. 1997). The algorithm uses six biome types that represent the architecture of an individual tree and the transmittance of vegetation elements.

\section{c. $A M S R-E$}

The Advanced Microwave Scanning Radiometer for the Earth Observing System (AMSR-E) instrument on the National Aeronautics and Space Administration (NASA) EOS Aqua satellite provides global passive microwave measurements of terrestrial, oceanic, and atmospheric variables for the investigation of global water and energy cycles (Njoku et al. 2003; Shibata et al. 2003). The satellite is in a sun-synchronous orbit with equatorial crossing at approximately 0130/1330 LST. The instrument measures brightness temperatures at six frequencies, 6.92, 10.65, 18.7, 23.8, 36.5, and 89.0 $\mathrm{GHz}$, with vertical and horizontal polarizations at each frequency, for a total of 12 channels. The incidence angle is fixed at $54.8^{\circ}$ with an altitude of $705 \mathrm{~km}$, and the AMSR-E provides a conically scanning footprint pattern with a swath width of $1445 \mathrm{~km}$. The mean footprint diameter ranges from $56 \mathrm{~km}$ at $6.92 \mathrm{GHz}$ to $5 \mathrm{~km}$ at $89 \mathrm{GHz}$. The AMSR-E observed brightness temperatures at 6,10 , and $18 \mathrm{GHz}$ are used in conjunction with a radiative transfer model to simultaneously retrieve the surface soil moisture, Ts, and VegWC. The radiative transfer model is run in an iterative fashion and these three variables are adjusted until the simulated brightness temperatures at the three channels closely match with the AMSR-E observed brightness tempera- 
tures at the same location (Njoku et al. 2003). The algorithm derived VegWC, soil moisture, and Ts global daily data is stored at the National Snow and Ice Data Center (NSIDC) Web site (see online at http:// www.nsidc.org/data/amsre). We acquired VegWC data from this Web site for our study regions and the time period of interest. Based on the algorithm, VegWC is retrieved from a radiative transfer model in which vegetation opacity is used to derive VegWC at low frequency (Njoku and Li 1999). The AMSR-E VegWC possibly has biased data values particularly on water bodies and bare soil areas. AMSR-E VegWC is derived from the surface roughness parameter incorporating effects both of vegetation and roughness (Njoku et al. 2003; Njoku and Chan 2006). Since roughness and vegetation have similar trends in their effects on the normalized polarization differences, the algorithm assumes the surface roughness parameter as VegWC (Njoku and Chan 2006). However, this assumption is acceptable only for smooth surface with vegetation. For example, a nonzero VegWC value in a desert area is only due to surface roughness. To avoid this error, we selected study regions primarily not including any water bodies and bare soil areas, and assumed that the selected regions have smooth vegetated surface and are not affected by any surface roughness other than vegetation. In the case of irrigated/flooded land surfaces, the soil moisture retrieved from the AMSR-E brightness temperature will show saturated values but the retrieval of VegWC will be unaffected.

\section{d. Data processing and analysis}

All MODIS datasets used in this study have a $1-\mathrm{km}$ spatial resolution while AMSR-E data is at $25 \mathrm{~km}$ with a different map projection type. Thus, in this study all datasets had to be resampled to be consistent with each other. All 1-km MODIS data were converted to $25-\mathrm{km}$ resolution as AMSR-E data, and the different spatial projection types between MODIS and AMSR-E were changed to the same AMSR-E geographical projection. The sinusoidal projection of MODIS datasets was converted into the AMSR-E geographical projection by the nearest neighbor method with the help of MODIS reprojection tool (developed by NASA), and 25 pixels of 1-km MODIS data were aggregated and averaged to compose the $25-\mathrm{km}$ spatial resolution. Then each dataset has been averaged for the 3-month summer season (9 June-12 September). When datasets are resampled, errors are inevitable. To minimize this error, we removed the cloud-contaminated MODIS data pixels based on the data retrieval quality information provided for every pixel and then analyzed the standard deviation for each process. In addition, we exclusively considered natural vegetation types (from 1 to 10 in the IGBP classification) for this analysis of the variables with the land-cover types. Permanent wet lands are possible to have contaminated retrieval especially for VegWC as it is mentioned in section $2 b$, and croplands should be considered more with the effects from human activity as well as climatic effects. Linear and nonlinear regression analyses were conducted to find correlations between the variables, and one of the variables was color coded into the two-variable relationship. The value of NVegWC was color coded in the Ts-NDVI relationship.

\section{e. $N V e g W C$}

The asymptotic relationship between NDVI and LAI has limited application to direct relationships between the variables (Clevers 1989; Carlson and Ripley 1997). In Fig. 3, NDVI shows rapid increase with LAI in low NDVI areas. The slow NDVI increase region in this regime has been accepted due to a surface almost fully covered by leaves (Curran 1983), and these asymptotic thresholds in which NDVI is saturated vary with vegetation type, age, and leaf water content (Paltridge and Barber 1988). Moreover, Ceccato et al. (2001, 2002) found that NDVI and VegWC did not covary in a simple fashion, which may be attributed to differences between biomes in contrasting climatic regimes. A decrease in chlorophyll content, which is considered to reflect a decrease in NDVI, does not directly indicate a decrease in VegWC and vice versa. Larger vegetation structures are likely to have higher vegetation water content. For example, VegWC values for deciduous broadleaf forests and mixed forests showed 2.33 and $2.35 \mathrm{~kg} \mathrm{~m}^{-2}$ on average, respectively, while those in savanna and shrubland areas showed 1.14 and $1.23 \mathrm{~kg}$ $\mathrm{m}^{-2}$, respectively. To examine the indirect relationships between the variables, we propose a new variable, the Normalized Vegetation Water Content (NVegWC) defined as VegWC per unit plant leaf area (the ratio of VegWC and LAI), which is linked with the leaf water conservation mechanism. It is a very useful descriptor especially when we compare vegetation across biomes that may have different species of vegetation with different leaf area indices and vegetation water contents. Our intent with calculating NVegWC was to facilitate a biome-to-biome comparison of vegetation water content and its relationship with other variables such as NDVI.

\section{Results}

Figure 4 shows distributions of each variable for the three regions for 2003 and 2004, and every pixel in each 


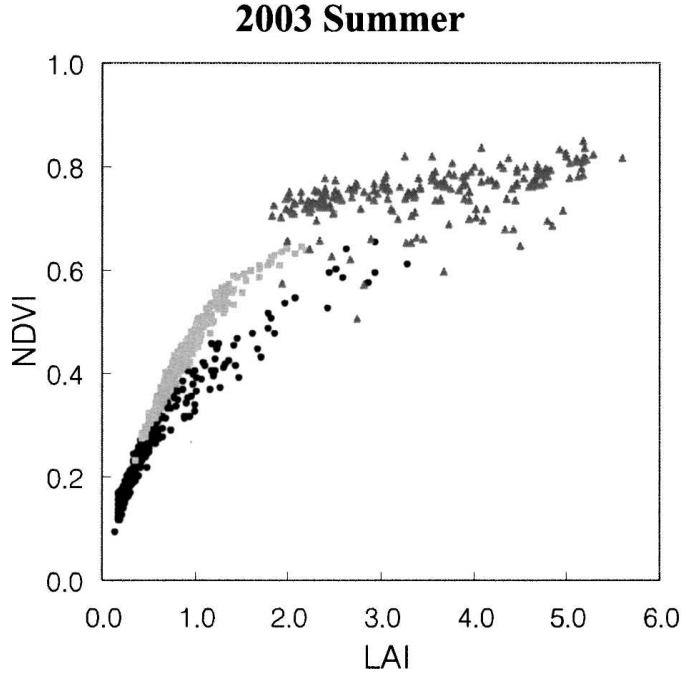

FIG. 3. NDVI and LAI ( NAMS,

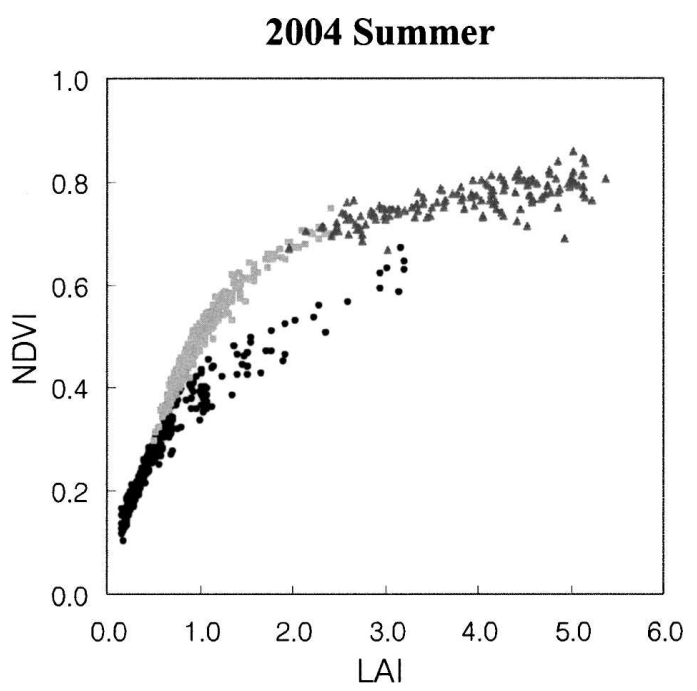

IHOP, and $\boldsymbol{\Delta}$ Tifton, GA). box is at a resampled $25-\mathrm{km}$ spatial resolution as mentioned above. We observe from the figure that the arid region of NAMS has an NDVI of $0.2-0.3$ whereas that in the humid region of Georgia is $0.6-0.8$. The VegWC and Ts also show a sharp contrast. Whereas the arid region has VegWC of $0-1.5 \mathrm{~kg} \mathrm{~m}^{-2}$ and Ts of 305-320 $\mathrm{K}$, the humid region has VegWC of $1.5-3.0 \mathrm{~kg} \mathrm{~m}^{-2}$ and Ts of 290-310 K. This shows the sharp contrasts between the different climatic regions. Also, we observe that though there is some interannual variability (cf. summer 2003 and summer 2004). The spatial patterns between summers 2003 and 2004 are quite similar for all the three locations and for all variables. The biggest difference in the spatial patterns between summers 2003 and 2004 is observed for Ts at Tifton and this is due to the large difference in the precipitation for the 2 yr (see Fig. 2).

a. The relationship of VegWC with NDVI and LAI (research questions 1 and 2)

Figure 5 shows the relationship of VegWC with NDVI and LAI for each study region. This relationship for each study region reflects its general climatic characteristics. These relationships can be generalized to the fact that VegWC varies less with low NDVI or LAI especially in the NAMS region, and with the increase of NDVI or LAI, the variation of VegWC is higher. VegWC in its relationship with NDVI and LAI shows very similar distributing patterns in the NAMS and IHOP regions, but in Tifton, the variation of VegWC with LAI is much greater then that with NDVI. Considered with the asymptotic relationship between NDVI and LAI mentioned in section 2f, Fig. 5a shows the NDVI saturation zone around 0.8 in Tifton, indicating that most vegetation shows maximum NDVI during the summer season in Georgia.

NVegWC, the ratio of VegWC and LAI, is noticeable in its relation with NDVI. Figure 6 shows a relatively strong relationship especially in the NAMS region with high R-square values. A general description of this relationship is high NVegWC with low NDVI. It is also remarkable that these statistical correlations become weaker in a more humid environment like Tifton. This well supports the fact that vegetation in more arid or semiarid areas is more dependent on the water condition of its environment. Figure 7 shows the NVegWC variation range for each land-cover type. Even in the same vegetation type, NVegWC variations are different in each region, and the average values in the NAMS region are generally higher with wider variation range while Tifton shows much less variation of NVegWC with lower average values than the other regions. The major types of vegetation in the NAMS region (shrublands and savannas) show relatively high NVegWC with very high variation. Thus, the negative exponential relationship between NVegWC and NDVI in Fig. 6 can be explained as the tendency of vegetation behavior, which is high water-leaf vegetation with low NDVI.

\section{b. The relationship between $T s, N D V I$, and NVegWC (research question 3)}

We investigated how surface temperature varies with NDVI and VegWC. Figures 8a,b show a general description of the relationship between Ts and NDVI (or vegetation greenness) and the relationship diagrams for the study regions, respectively. This relationship, 
NAMS Region (2003)

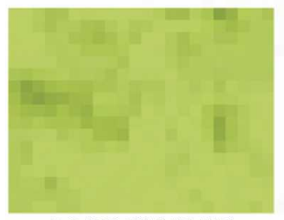

MODIS NDVI

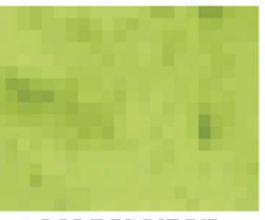

MODIS NDVI

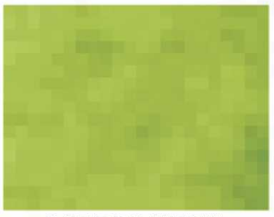

MODIS NDVI

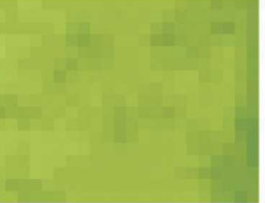

MODIS NDVI

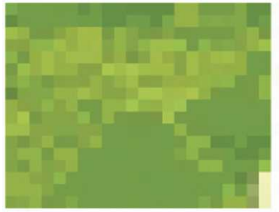

MODIS NDVI

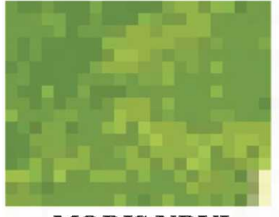

MODIS NDVI

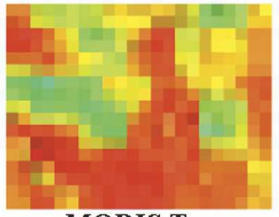

MODIS Ts

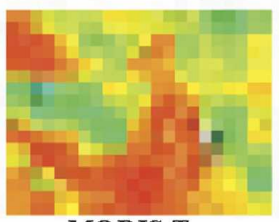

MODIS Ts

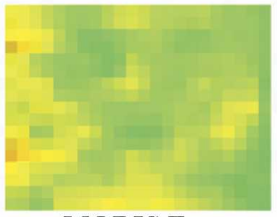

MODIS Ts

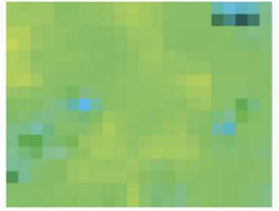

MODIS Ts

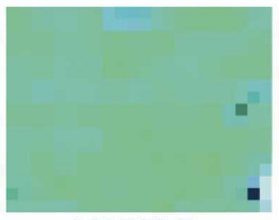

MODIS Ts

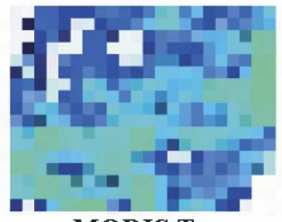

MODIS Ts

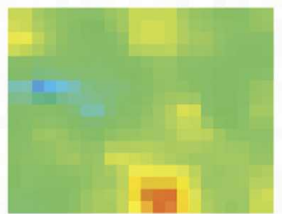

AMSR VegWC

NAMS Region (2004)

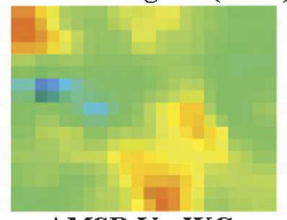

AMSR VegWC

IHOP Region (2003)

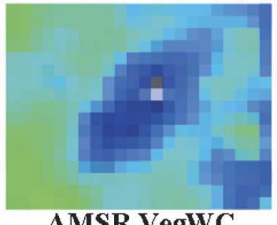

AMSR VegWC

\section{IHOP Region (2004)}

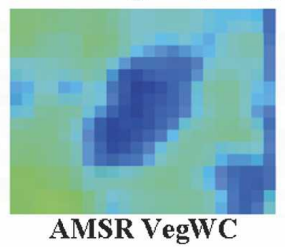

Tifton, GA (2003)

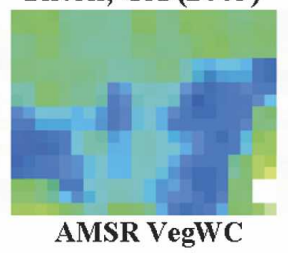

Tifton, GA (2004)

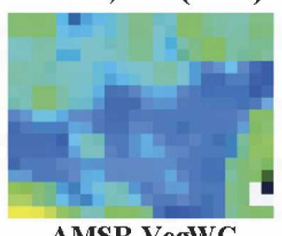

AMSR VegWC

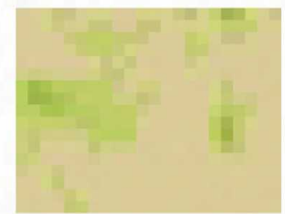

MODIS LAI

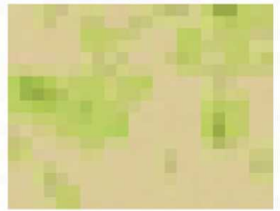

MODIS LAI

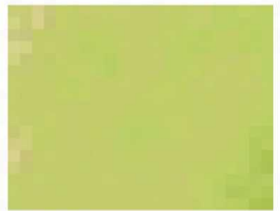

MODIS LAI

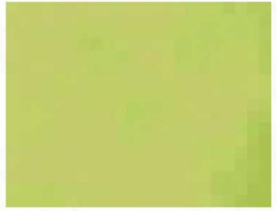

MODIS LAI

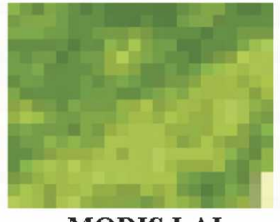

MODIS LAI

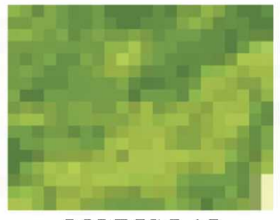

MODIS LAI

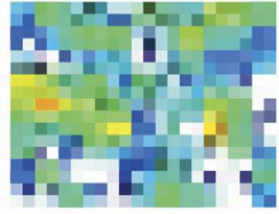

NVegWC

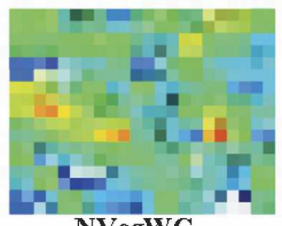

NVegWC

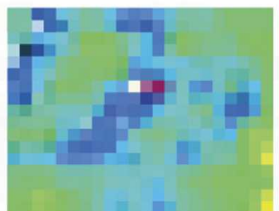

NVegWC

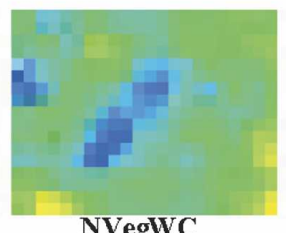

NVegWC

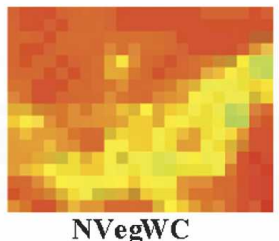

NVegWC

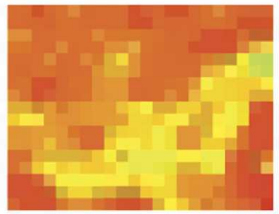

NVegWC
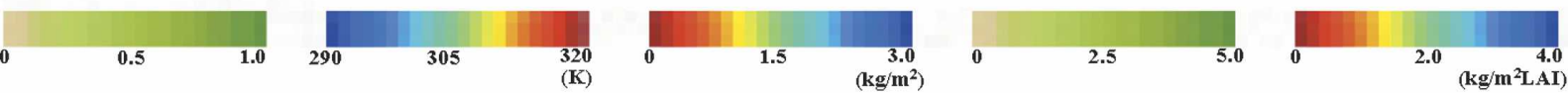

FIG. 4. Scanned images of NDVI, Ts, VegWC, LAI, and NVegWC for the three regions for the summers of 2003 and 2004. 
2003 Summer

(a)

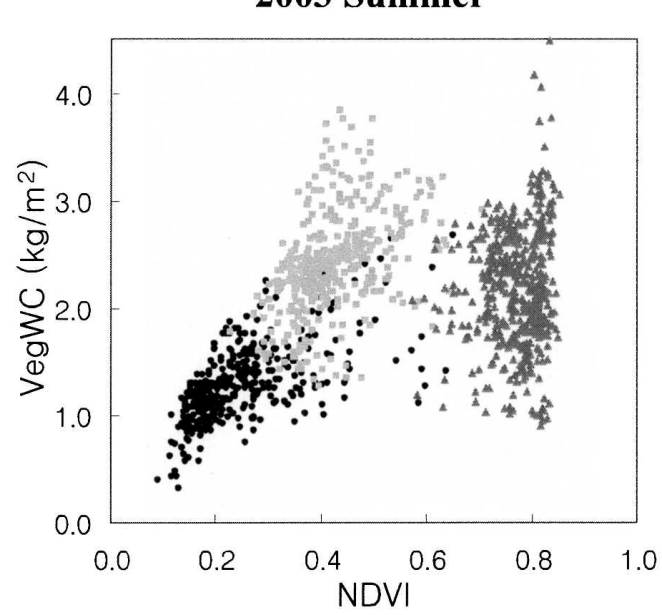

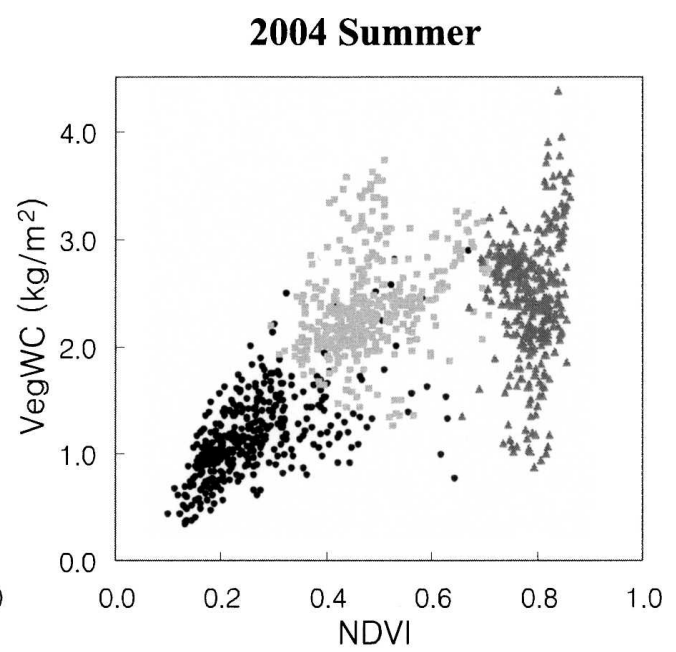

2004 Summer

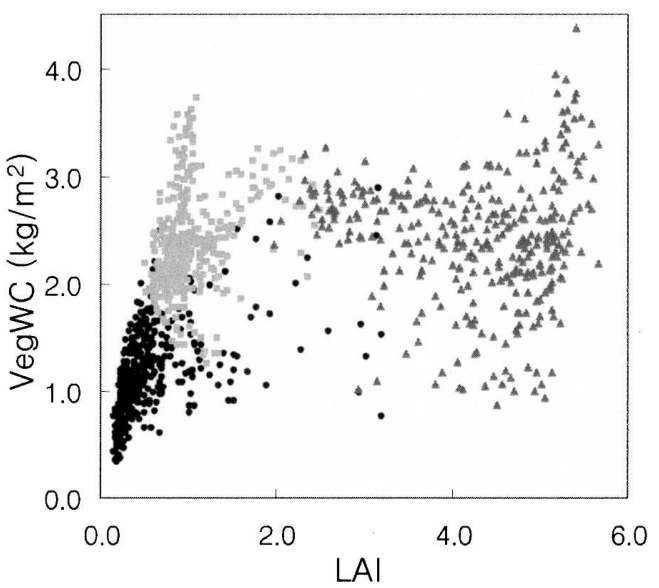

(b)

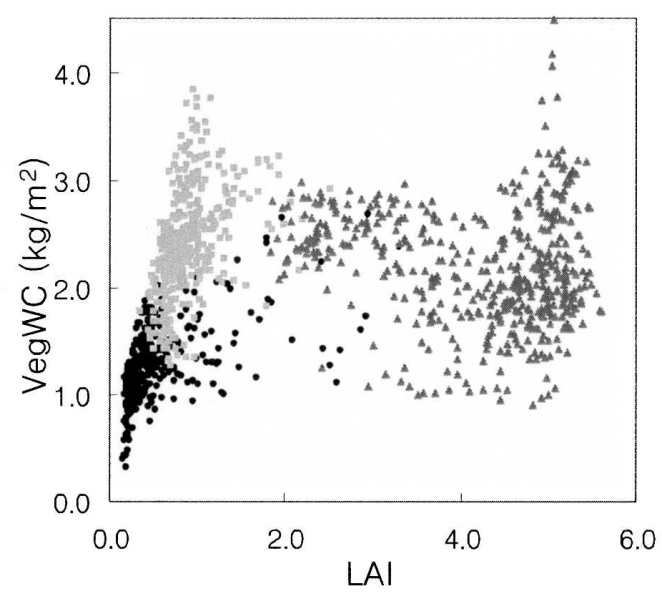

FIG. 5. (a) VegWC-NDVI and (b) VegWC-LAI relationships

NAMS,

IHOP, and $\boldsymbol{\Delta}$ Tifton, GA).

termed as the TvX relationship, has been examined in many previous studies as a fundamental descriptor of the land surface state related with surface moisture availability and hence ET (Nemani and Running 1989; Sandholt et al. 2002). The geometry of the TvX relationship shows regional, climatic, and biome dependence (Goetz 1997; Sandholt et al. 2002), and our study regions fall within the triangle-shaped geometry, showing a good contrast of general climatic and vegetation characteristics in each study region. The clustering of the points from each of the three regions on the TvX plot shows the importance of climate and vegetation characteristics. The TvX relationship of the NAMS region in the figure is distributed in the range of the upper and left area, which indicates very low vegetation and a dry condition with high potential evaporation. The IHOP region in this relationship shows relatively wetter climate than the NAMS region with more partial canopy. Tifton, on the other hand, shows full vegetation and a very wet climate with high potential transpira- tion. With low evaporation, Ts of bare soil is much higher than that of plant canopies, and therefore a negative slope exists along the dry or warm edge. This slope in the TvX relationship is steeper in dryer conditions (Goetz 1997; Nemani et al. 1993). In Fig. 9, the steepness of the negative slopes is higher in the NAMS region.

Through the regression analyses of the TvX relationship, the statistical correlation in the NAMS region is much stronger, compared with Tifton. NVegWC has been color coded into this TvX relationship in Fig. 9, showing high $\mathrm{NVegWC}$ distributed in higher Ts and lower NDVI areas. With the negative exponential relationship between NVegWC and NDVI explained in the previous section, this analysis also supports our finding that more water exists in vegetation leaves of more arid environments. Arid regions with low NDVI, however, do not have a continuous canopy cover but a sparse coverage (e.g., clumps of vegetation interspersed with bare soil area). Since Ts of bare soils is always 

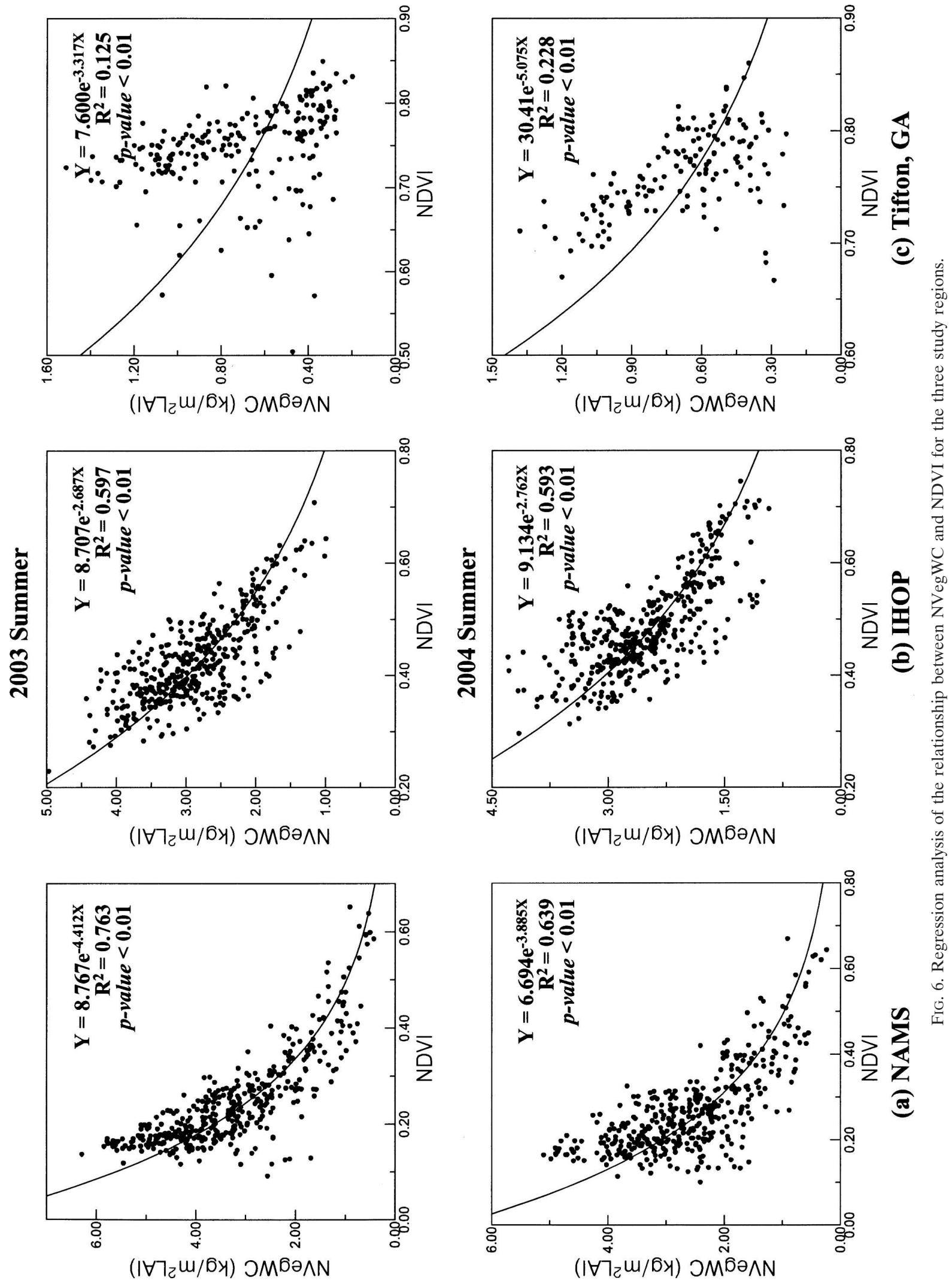


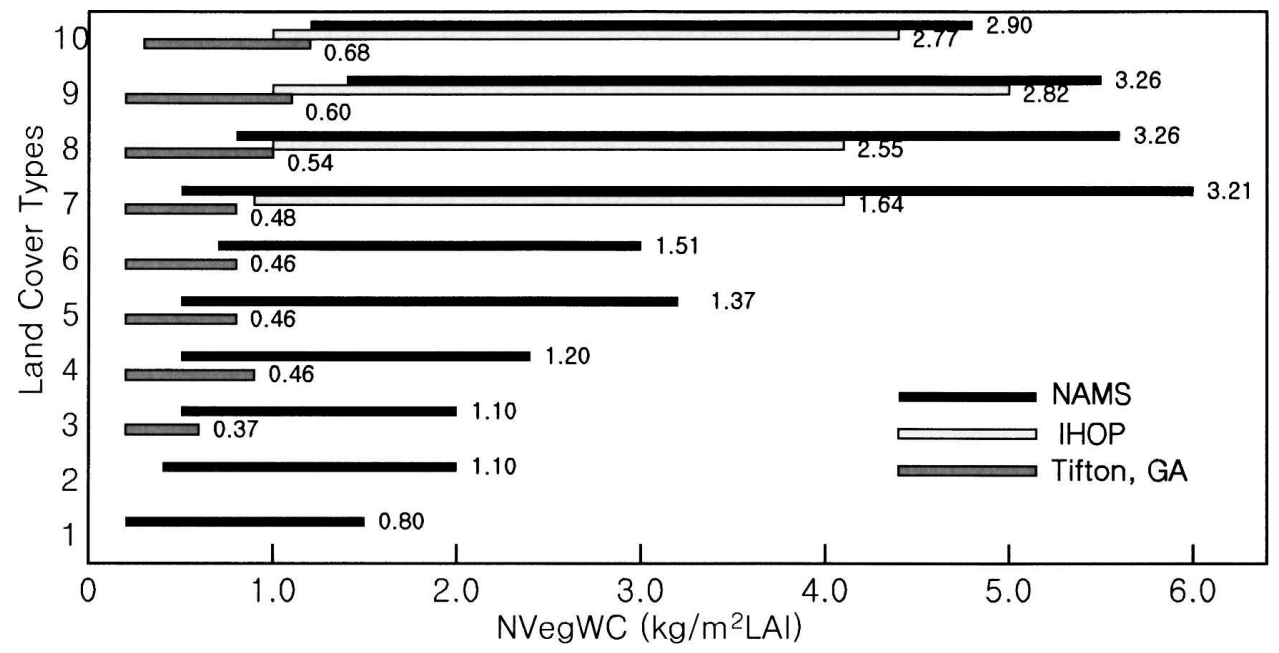

FIG. 7. NVegWC variation in different land-cover types for the summer seasons of 2003 and 2004 (the numbers of land-cover types follow the IGBP classification). The denoted numbers are the NVegWC average values for each range bar.

larger, for daytime measurements, than that of transpiring vegetation in the summer season, Ts of the NAMS region is higher than that of the other two regions, considered in this study (Figs. 8 and 9). Because of this influence of the discontinuous vegetation coverage on Ts, the relationship between $\mathrm{NVegWC}$, and Ts in such arid areas can be overstated, but the NVegWC-NDVI relation provides enough clues for the conclusions reached in this study.

\section{Discussion and conclusions}

We have performed analyses of four land surface variables (VegWC, NDVI, LAI, and Ts) to investigate their interactions, using satellite-derived data of AMSR-E and MODIS. Spatial variation of the relationship between them has been mainly focused through selecting three climatic characteristic regions in North America: the NAMS region, the IHOP region, and Tifton, Georgia. Each region shows typical trends of arid or semiarid and humid areas. During these analyses, we introduced a new variable, $\mathrm{NVegWC}$, and obtained remarkable results. The negative relationship between NVegWC and NDVI and between Ts and NDVI shows more water existence in plant leaves in more arid areas, and the determination coefficients for those relationships of each region in the regression analyses explain the dependency of vegetation on the water condition. It is generally assumed that the greenness of vegetation is related to photosynthesis, which is dependent on solar radiation and the amount of carbon dioxide. The water content in vegetation is also utilized for the photosynthesis by which oxygen is released into the atmosphere, causing plant transpiration. The water amount in vegetation is closely related to different vegetation types than the greenness of vegetation, which is considered to be an indicator of photosynthesis. The photosynthesis process in vegetation is controlled under the water stress condition. There are many physiological and climate factors influencing the vegetation water stress such as soil moisture and precipitation, and surface temperature is one of the indicators of increased water stress. During the summer months, an increase in Ts implies an increase in the water stress of vegetation, all other factors being equal, and moreover in arid regions Ts is more likely to impact the water stress of vegetation than other factors. Vegetation physiologically responds to a high water stress condition by closing the stomata to control losing moisture and by having a deep and widely spread root system to reach water sources in deeper soil (Tanguiling et al. 1987; Cohen et al. 2005). There are also some species, especially in the arid area, that store more water in leaves during rainy season (Kramer 1983). Weighing the actual amount of water in different plant types separately for leaves, stems, and fruits/flowers, Sims and Gamon (2003) showed that during a drought, deciduous shrubs contain more water in their leaves than in evergreen tree leaves. These physiological responses of vegetation have been considered as an adaptation mechanism to the environment (Kramer 1983), and they would be present more in vegetation in arid regions where the water stress is a normal situation. Hence, the dominant vegetation in the arid area like the NAMS region is more likely to be adapted to their environment in a way to minimize their water loss than that in a more humid area like Tifton. In this study, LAI 

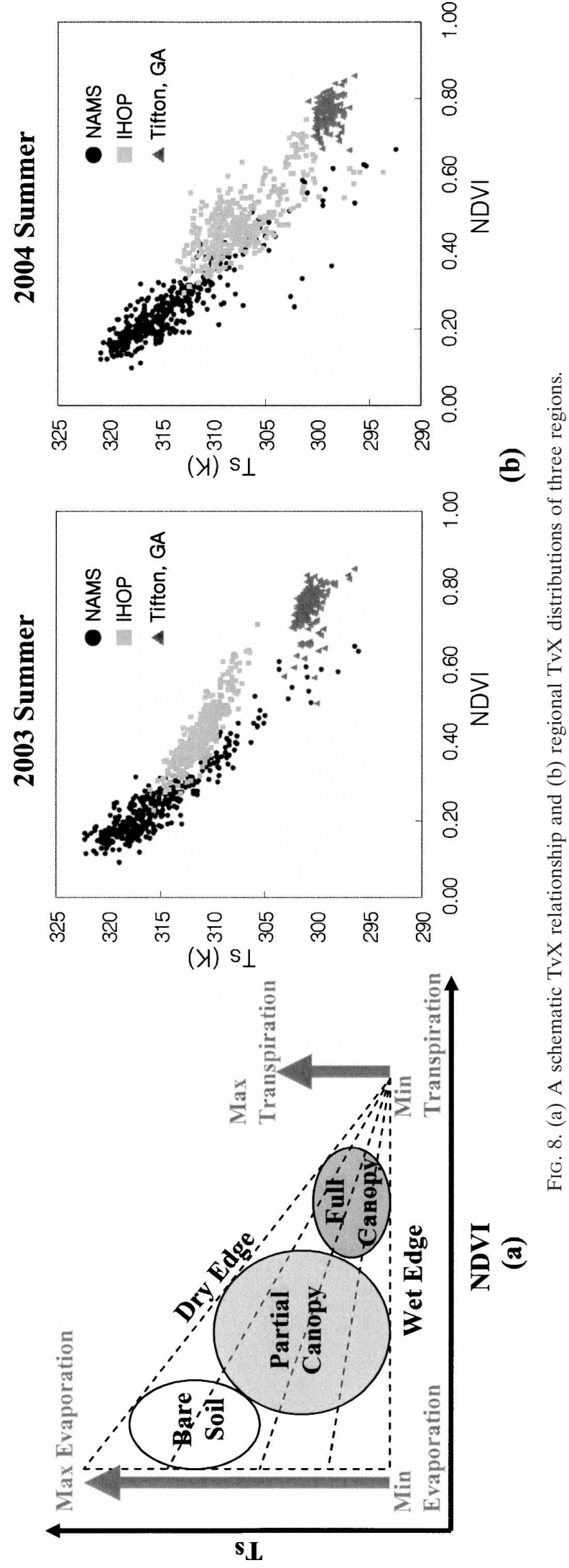

shows significant regional difference in values (NAMS: 0-2, IHOP: 0.5-2.5, and Tifton: 1.5-6), but the regional differences of $\mathrm{VegWC}$ values between the three regions is not as much (NAMS: $0-3 \mathrm{~kg} \mathrm{~m}^{-2}$, IHOP: $1-4 \mathrm{~kg} \mathrm{~m}^{-2}$, and Tifton: $1-4 \mathrm{~kg} \mathrm{~m}^{-2}$ ). This can be explained as the vegetation amount varies significantly under the regional climate condition, but the vegetation response shows a tendency to conserve water.

The definition of VegWC derived from AMSR-E, however, is area-averaged water content in the vertical column of vegetation overlying soil $\left(\mathrm{kg} \mathrm{m}^{-2}\right.$; Njoku and Li 1999). The surface roughness is related to the vegetation opacity, and this determines VegWC under the assumption of a uniformly vegetated surface in a unit area. This approach is derived from a linear relationship between the vegetation opacity and vegetation water content (Jackson and Schmugge 1991; Le Vine and Karam 1996). Hence, VegWC can be also defined as total water mass in vegetation per unit of ground area, including leaves as well as stalks and branches. Unlike VegWC, LAI does not represent the whole plant in vegetation but only leaves. Thus, NVegWC derived as the ratio VegWC and LAI should be interpreted carefully because it can be overestimated as actual water content per unit leaf.

We have not used Rainfall Use Efficiency (RUE) in this work. In particular, it may be better to think of vegetation classes in terms of water-use efficiency classifications rather than a species-based classifier. For example, grasslands in arid regions have completely different water-use and hydrological characteristics than in humid regions.

However, this study is significant in that this provides general information about the physiological behavior of vegetation against its environment in a more regional scale. Remote sensing or ground-based observation data about the accurate water amount in different parts of vegetation for spatial analyses in more global scales are required for more accurate research in various spatial scales. Further research about this phenomenon with the relation to plant photosynthesis and the variation of the amount of carbon dioxide amount in the near plant-atmosphere will support this study.

Acknowledgments. The authors gratefully acknowledge the support of NASA Land Surface Hydrology Program, NAG5-8875 (Program Manager Dr. Jared Entin) and the Office of Global Programs NA04OAR4310165, (Program Manager Dr. Jin Huang). Discussions with Dr. Eni Njoku of the Jet Propulsion Laboratory and Ethan Gutman of the Department of Geology at the University of Colorado have helped in carrying out this work. 

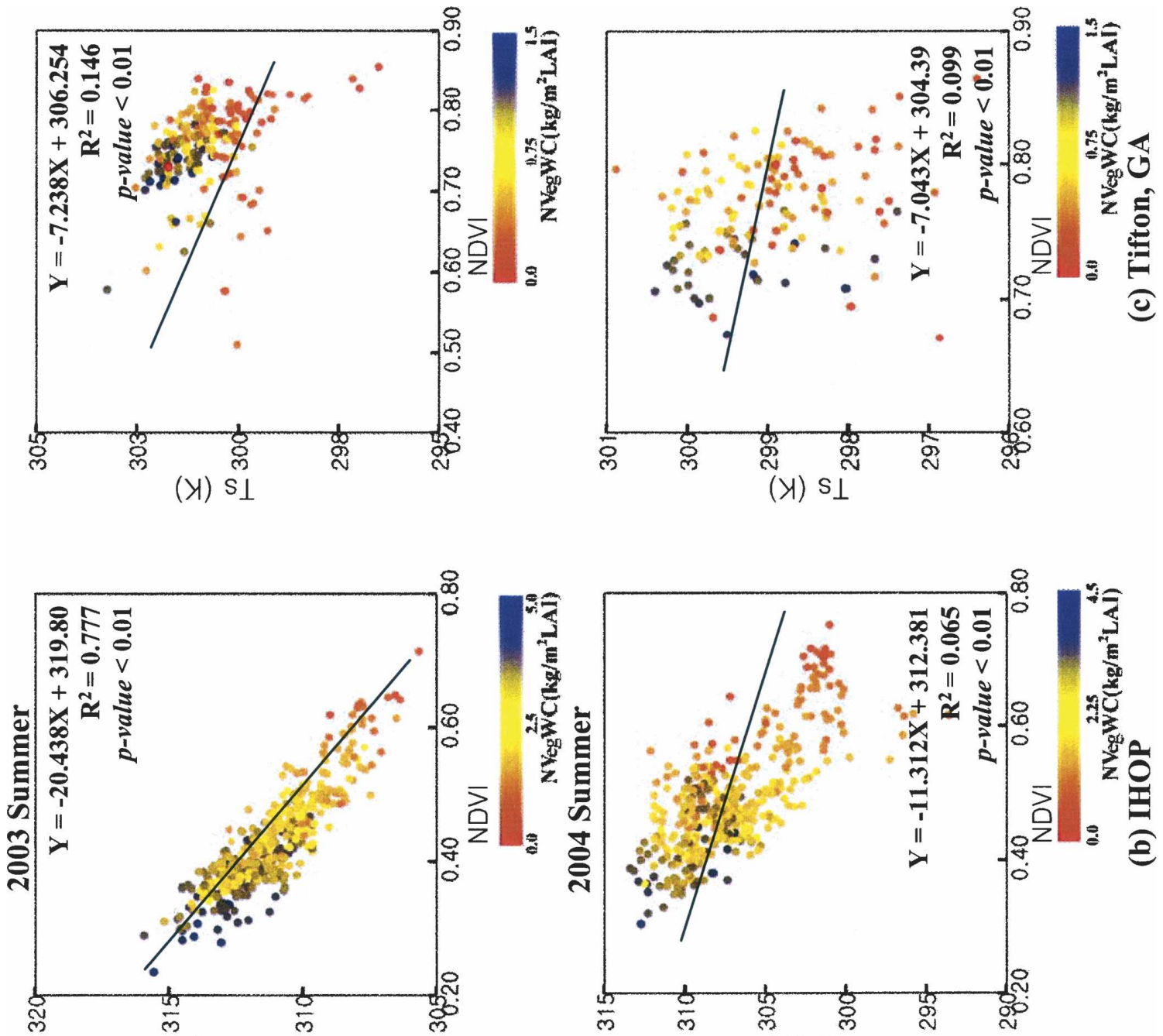

(X) $S \perp$
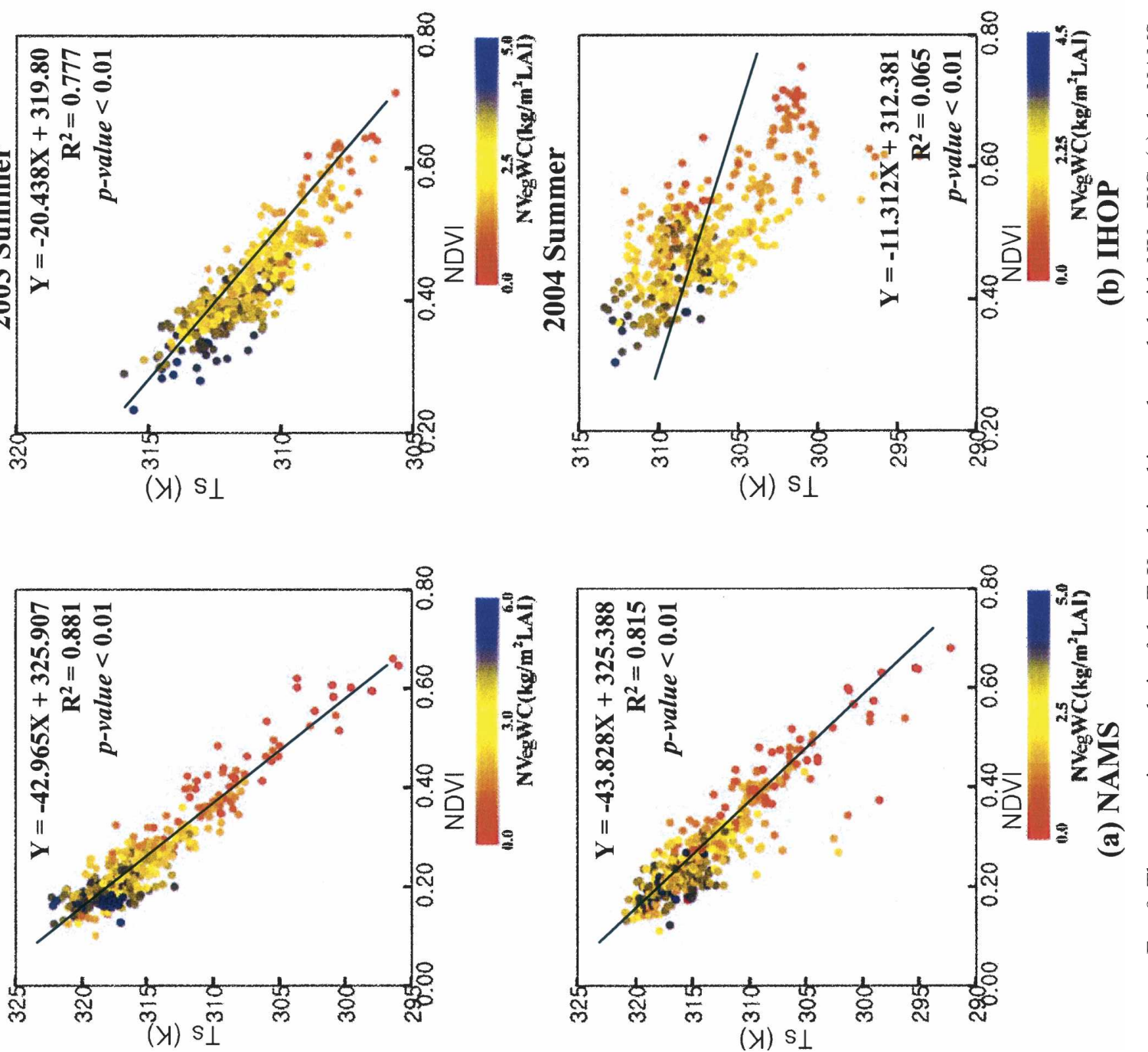


\section{REFERENCES}

Betts, R. A., P. M. Cox, S. E. Lee, and F. I. Woodward, 1997: Contrasting physiological and structural vegetation feedbacks in climate change simulations. Nature, 387, 796-799.

Bosch, D. D., F. M. Davis, and J. M. Sheridan, 1999: Rainfall characteristics and special correlation for the Georgia coastal plain. Trans. ASAE, 42 (6), 1637-1644.

Bounoua, L., and Coauthors, 1999: Interaction between vegetation and climate: Radiative and physiological effects of doubled atmospheric $\mathrm{CO}_{2}$. J. Climate, 12, 309-324.

Carlson, T. N., and D. A. Ripley, 1997: On the relation between NDVI, fractional vegetation cover, and leaf area index. Remote Sens. Environ., 62, 241-252.

Ceccato, P., S. Flasse, S. Tarantola, S. Jacquemoud, and J. Gregoire, 2001: Detecting vegetation leaf water content using reflectance in the optical domain. Remote Sens. Environ., 77, 22-33.

- - — - and J. Gregoire, 2002: Designing a spectral index to estimate vegetation water content from remote sensing data (part 2). Remote Sens. Environ., 82, 198-207.

Clevers, J. G. P. W., 1989: The application of a weighted infraredred vegetation index for estimating leaf area index by correcting for soil moisture. Remote Sens. Environ., 29, 25-37.

Cohen, Y., V. Alchanatis, M. Meron, Y. Saranga, and J. Tsipris, 2005: Estimation of leaf water potential by thermal imagery and spatial analysis. J. Exp. Bot., 56 (417), 1843-1852.

Curran, P. J., 1983: Multispectral remote sensing for the estimation of green leaf area index. Philos. Trans. Roy. Soc. London, 309A, 257-270.

Defries, R. S., M. Hansen, J. R. G. Townshend, and R. Sohlberg, 1998: Global land cover classification at $8 \mathrm{~km}$ spatial resolution: The use of training data derived from Landsat imagery in decision tree classifiers. Int. J. Remote Sens., 19 (16), 31413168.

Friedl, M. A., and Coauthors, 2002: Global land cover mapping from MODIS: Algorithms and early results. Remote Sens. Environ., 83, 287-302.

Goetz, S. J., 1997: Multi-sensor analysis of NDVI, surface temperature and biophysical variables at a mixed grassland site. Int. J. Remote Sens., 18, 71-94.

Hansen, M. C., R. S. Defries, J. R. G. Townshend, and R. Sohlberg, 2000: Global land cover classification at $1 \mathrm{~km}$ spatial resolution using a classification tree approach. Int. J. Remote Sens., 21 (6-7), 1331-1364.

Huete, A., K. Didan, T. Miura, E. P. Rodriguez, X. Gao, and L. G. Ferreira, 2002: Overview of the radiometric and biophysical performance of the MODIS vegetation indices. Remote Sens. Environ., 83, 195-213.

Jackson, T. J., and T. J. Schmugge, 1991: Vegetation effects on the microwave emission of soils. Remote Sens. Environ., 36, $203-$ 212.

Justice, C. O., and Coauthors, 1998: The Moderate Resolution Imaging Spectroradiometer (MODIS): Land remote sensing for global change research. IEEE Trans. Geosci. Remote Sens., 36 (4), 1228-1249.

— J. R. G. Townshend, E. F. Vermote, E. Masuoka, R. E. Wolfe, N. Saleous, D. P. Roy, and J. T. Morisette, 2002: An overview of MODIS land data processing and product status. Remote Sens. Environ., 83, 2-15.

Kleidon, A., and M. Heimann, 1998: Optimized rooting depth and its impacts on the simulated climate of an atmospheric general circulation model. Geophys. Res. Lett., 25, 345-348.
Kramer, P. J., 1983: Water Relations of Plants. Academic Press, 489 pp.

_, and J. S. Boyer, 1995: Water Relations of Plants and Soils. Academic Press, 495 pp.

Kurc, S. A., and E. E. Small, 2004: Dynamics of evapotranspiration in semiarid grassland and shrubland during the summer monsoon season, central New Mexico. Water Resour. Res., 40, W09305, doi:10.1029/2004WR003068.

Le Vine, D. M., and M. A. Karam, 1996: Dependence of attenuation in a vegetation canopy on frequency and plant water content. IEEE Trans. Geosci. Remote Sens., 34, 1090-1096.

Lu, L., R. A. Pielke, G. E. Liston, W. J. Parton, D. Ojima, and M. Hartman, 2001: Implementation of a two-way interactive atmospheric and ecological model and its application to the central United States. J. Climate, 14, 900-919.

Myneni, R. B., F. G. Hall, P. J. Sellers, and A. L. Marshak, 1995: The interpretation of spectral vegetation indexes. IEEE Trans. Geosci. Remote Sens., 33 (2), 481-486.

_- R. Ramakrishna, R. Nemani, and S. Running, 1997: Estimation of global leaf area index and absorbed PAR using radiative transfer models. IEEE Trans. Geosci. Remote Sens., 35 (6), 1380-1393.

— , and Coauthors, 2002: Global products of vegetation leaf area and fraction absorbed PAR from year one of MODIS data. Remote Sens. Environ., 83, 214-231.

Neilson, R. P., 1986: High-resolution climatic analysis and southwest biogeography. Science, 232, 27-34.

Nemani, R., and S. Running, 1989: Estimation of regional surface resistance to evapotranspiration from NDVI and Thermal-IR AVHRR data. J. Appl. Meteor., 28, 276-284.

_ L. Lierce, S. Running, and S. Goward, 1993: Developing satellite-derived estimates of surface moisture status. J. Appl. Meteor., 32, 548-557.

Njoku, E. G., and L. Li, 1999: Retrieval of land surface parameters using passive microwave measurements at 6-18 GHz. IEEE Trans. Geosci. Remote Sens., 37, 79-93.

_ , and T. Chan, 2006: Vegetation and surface roughness effects on AMSR-E land observations. Remote Sens. Environ., 100 (2), 190-199.

_ T. Jackson, V. Lakshmi, T. Chan, and S. Nghiem, 2003: Soil moisture retrieval from AMSR-E. IEEE Trans. Geosci. Remote Sens., 41, 215-229.

Noilhan, J., and S. Planton, 1989: A simple parameterization of land surface processes for meteorological models. Mon. Wea. Rev., 117, 536-549.

Paltridge, G. W., and J. Barber, 1988: Monitoring grassland dryness and fire potential in Australia with NOAA/AVHRR data. Remote Sens. Environ., 25, 381-394.

Pielke, R. A., 2001: Influence of the spatial distribution of vegetation and soils on the prediction of cumulative rainfall. Rev. Geophys., 39 (2), 151-177.

_ , R. Avissar, M. Raupach, A. J. Dolman, X. Zeng, and A. S. Denning, 1998: Interaction between the atmosphere and terrestrial ecosystems: Influence on weather and climate. Global Change Biol., 4, 101-115.

_, R. L. Walko, L. T. Steyaert, P. L. Vidale, G. E. Liston, W. A. Lyons, and T. N. Chase, 1999: The influence of anthropogenic landscape changes on weather in South Florida. Mon. Wea. Rev., 127, 1663-1673.

Pitman, A. J., 1991: A simple parameterization of sub-grid scale open water for climate models. Climate Dyn., 6, 99-112.

Sandholt, I., K. Rasmussen, and J. Andersen, 2002: A simple interpretation of the surface temperature/vegetation index 
space for assessment of surface moisture status. Remote Sens. Environ., 79, 213-224.

Schenk, H. J., and R. B. Jackson, 2002: The global biogeography of roots. Ecol. Monogr., 72 (3), 311-328.

Schlesinger, W. H., J. F. Reynolds, G. L. Cunningham, L. F. Huenneke, W. M. Jarrell, R. A. Virginia, and W. G. Whitford, 1990: Biological feedbacks in global desertification. Science, 247, 1043-1048.

Sellers, P. J., and Coauthors, 1996: Comparison of radiative and physiological effects of doubled atmosphere $\mathrm{CO}_{2}$ on climate. Science, 271, 1402-1406.

Shibata, A., K. Imaoka, and T. Koike, 2003: AMSR/AMSR-E level 2 and 3 algorithm developments and data validation plans of NASDA. IEEE Trans. Geosci. Remote Sens., 41, 195-203.

Sims, D. A., and J. A. Gamon, 2003: Estimation of vegetation water content and photosynthetic tissue area from spectral reflectance: A comparison of indices based on liquid water and chlorophyll absorption features. Remote Sens. Environ., 84, 526-537.

Small, E. E., and S. A. Kurc, 2003: Tight coupling between soil moisture and the surface radiation budget in semiarid environments: Implications for land-atmosphere interactions. Water Resour. Res., 39, 1278, doi:10.1029/2002WR001297.

Swetnam, T. W., and J. L. Betancourt, 1998: Mesoscale disturbance and ecological response to decadal climatic variability in the American Southwest. J. Climate, 11, 3128-3147.

Tanguiling, V. C., E. B. Yambao, J. C. O. Toole, and S. K. De
Datta, 1987: Water stress on leaf elongation, leaf water potential, transpiration and nutrient uptake of rice, maize and soybean. Plant Soil, 103, 155-168.

Tucker, C. J., 1979: Red and photographic infrared linear combination for monitoring vegetation. Remote Sens. Environ., 8, $127-150$.

Wan, Z., and Z. L. Li, 1997: A physics-based algorithm for retieving land-surface emissivity and temperature from EOS/ MODIS data. IEEE Trans. Geosci. Remote Sens., 35, 980996.

Weckwerth, T. M., and Coauthors, 2004: An overview of the International $\mathrm{H}_{2} \mathrm{O}$ Project (IHOP_2002) and some preliminary highlights. Bull. Amer. Meteor. Soc., 85, 253-277.

Weiss, J. L., D. S. Gutzler, J. E. A. Coonrod, and C. N. Dahm, 2004: Seasonal and inter-annual relationships between vegetation and climate in central New Mexico, USA. J. Arid Environ., 57, 507-534.

Xue, Y., P. J. Sellers, J. L. Kinter, and J. Shukla, 1991: A simplified biosphere model for global climate studies. J. Climate, 4, 345-364.

Zarco-Tejada, P. J., C. A. Rueda, and S. L. Ustin, 2003: Water content estimation in vegetation with MODIS reflectance data and model inversion methods. Remote Sens. Environ., 85, 109-124.

Zeng, X., R. E. Dickinson, A. Walker, and M. Shaikh, 2000: Derivation and evaluation of global 1-km fractional vegetation cover data for land modeling. J. Appl. Meteor., 39, 826-839. 